\title{
Comparison of Stage and Lymph Node Ratio in Young and Older Patients with Colorectal Cancer Operated in a Tertiary Hospital in Nepal
}

\author{
Bikal Ghimire, ${ }^{1}$ Yogendra Prasad Singh, ${ }^{1}$ Goran Kurlberg, ${ }^{2}$ Yvonne Wettergren ${ }^{3}$ \\ 'Department of Surgery, Institute of Medicine, Maharajgunj Medical Campus, Tribhuvan Universtiy, \\ Maharajgunj, Kathmandu, Nepal, ${ }^{2}$ Department of Surgery, Institute of Clinical Sciences, the Sahlgrenska \\ Academy at University of Gothenburg, Sahlgrenska University Hospital, Gothenburg, Sweden, ${ }^{3}$ Surgical- \\ Oncology Laboratory, Department of Surgery, Institute of Clinical Sciences, the Sahlgrenska Academy at \\ University of Gothenburg, Sahlgrenska University Hospital, Gothenburg, Sweden.
}

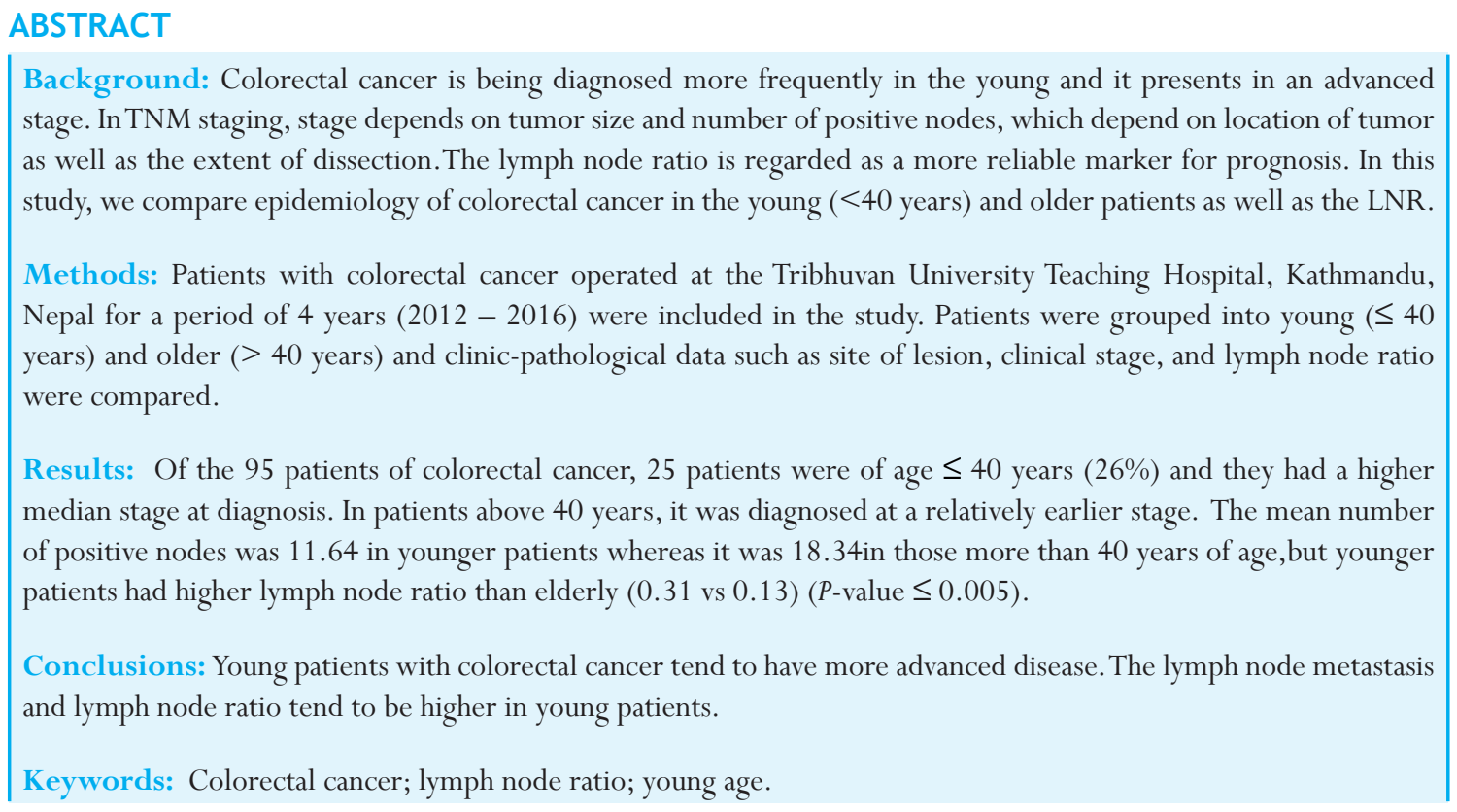

\section{INTRODUCTION}

There has been an increase in the incidence of colorectal cancer (CRC) especially in young patients in the developed countries. ${ }^{1}$ Over the last forty years, there has been an increase of about $75 \%$ in the incidence of carcinoma of rectum alone. ${ }^{2}$ According to the National health-program for colorectal cancer in Sweden, only $5 \%$ of all cases diagnosed from 2007-2011 occurred in patients less than 50 years of age. ${ }^{3}$ A review of the Surveillance, Epidemiology, and End Results (SEER) database of 7661 patients in United States with colorectal cancer from 1973 to 2005 revealed increase in the incidence of carcinoma of rectum,especially in young patients with age less than 40 years. ${ }^{4}$ Even in Asia, there is rapid increase in the burden of colorectal cancer with two to fourfold increase in countries like
China, Singapore, Korea. ${ }^{5}$

There is a delay in the diagnosis in young patients, probably due to lack of suspicion of malignancy leading to delay in further investigation. ${ }^{6} \mathrm{~A}$ review of 73 patients in a tertiary care hospital in Nepal during 8 years showed that $29 \%$ patients were below 40 years of age. ${ }^{7}$ More aggressive disease with poorly differentiated tumors such as mucinous and signet ring types are seen more commonly in young patients. ${ }^{8}$ However, even with advances in diagnosis and management, the five year survival remains poor in the Indian subcontinent. ${ }^{9}$ The prognosis in colorectal cancer patients depends on the nodal involvement, however the number and the location of lymph node removed influences it, which in turn is dependent on the operating surgeon. Lymphnode ratio (LNR) is the ratio of metastatic nodes to the number 
of total nodes dissected. In contrast to the number of positive lymph nodes alone, especially in stage III colon cancer, the LNR has been shown to reflect outcome. ${ }^{10}$

The aim of this study was to compare the location of the colorectal cancer, stage and lymphnode ratio in young ( $\leq 40$ years) and older patients.

\section{METHODS}

A cross sectional study of all patients with colorectal cancer managed at the Tribhuvan University Teaching Hospital, Kathmandu, Nepal was done for a period of 4 years (2012 - 2016). Inclusion criteria were all patients diagnosed with adenocarcinoma of colon and rectum and operated at the hospital. Colorectal cancer was grouped according to the primary lesion location; caecal, ascending, hepatic flexure and transverse colon as right colon; splenic flexure, descending colon and rectosigmoid junction as left colon;upper, mid and lower rectum as rectal cancer. Staging was done according to the TNM staging (AJCC cancer staging, Seventh edition 2010).

Patients with resectable colon cancer and upper rectal cancer underwent upfront surgery with curative intent. Those with resectable mid and lower rectal cancer underwent short course radiotherapy (25G in 5 fractions, $5 \mathrm{G} /$ day) and those with T4 lesion underwent full course therapy (45G, 1.5 Fraction).

Patients were grouped according to age ( $\leq 40$ years and $>40$ years) and clinicopathological data such as site of lesion,clinical Stage, LNR were compared along with the demographic data such as gender, age and ethnicity. Comparison of mean values was done with independent samples t-test and ANOVA and median values with Median Test and K-S test. Descriptive and qualitative variables were compared with Chi-square tests and $P$ values $<0.05$ were considered significant.

Ethical considerations The study was aligned to the principles of the Helsinki Declaration. Ethical approval was obtained from the Ethical Review Committee of Nepal Health Research Council.

\section{RESULTS}

There were 95 patients managed with the diagnosis of colorectal cancer during the study period; 60 patients were males and 35 females. Twenty-five of the patients were of age less than or equal to 40 years $(26 \%)$. One patient had familial adenomatous polyposis (FAP)with adenocarcinoma in the colon and underwent total proctocolectomy. Most patients had involvement of the right colon (43\%) and rectal cancer was present in $18.9 \%$ of the patients. There was a slight predominance of the involvement of colon compared torectum in both the young and older patients (56\% and $54.4 \%$, respectively) (Figure 1).

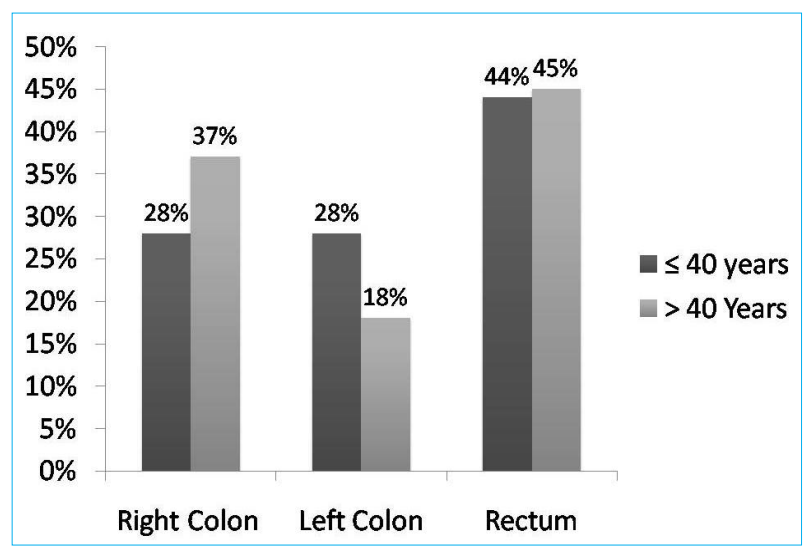

Figure 1. Distribution of adenocarcinoma in the young and older patients.

A study of the distributions of Tumor Stages among patients in two groups (based upon the age category they belonged to) showed that patients below 40 years of age had a higher median stage at diagnosis, whereas patients above 40 years were diagnosed at a relatively earlier stage (Stage IIIB compared to Stage IIA, IQR: Stage IIA -Stage IIIB). The significance was tested using a Mann Whitney $U$ test and the difference in ranks was shown to be statistically significant $(U=556.5, p=0.005)$. (Table 1) (Figure 2)

\section{Table 1. Distributions of Tumor Stages among}

patients in two groups.

\begin{tabular}{|c|c|c|c|c|}
\hline Age Category & Median & Minimum & Maximum & $\mathrm{N}$ \\
\hline $\begin{array}{l}\leq 40 \text { Years of } \\
\text { Age }\end{array}$ & $\begin{array}{l}\text { Stage } \\
\text { IIIB }\end{array}$ & $\begin{array}{l}\text { Stage } \\
\text { IIA }\end{array}$ & Stage IV & 25 \\
\hline $\begin{array}{l}>40 \text { Years } \\
\text { of Age }\end{array}$ & $\begin{array}{l}\text { Stage } \\
\text { IIA }\end{array}$ & Stage 0 & Stage IV & 70 \\
\hline Total & $\begin{array}{l}\text { Stage } \\
\text { IIA }\end{array}$ & Stage 0 & Stage IV & 95 \\
\hline
\end{tabular}

Test Statistics ${ }^{\mathrm{a}}$

Tumor Stage

Mann-Whitney U

556.500

Wilcoxon W

3041.500

Z

$-2.782$

Asymp. Sig. (2-tailed)

.005

The mean number of lymph nodes dissected was higher in those less than 40 years of age (29.82 vs 18.34), however, the difference was not statistically significant. The mean number of positive nodes was 11.64 in younger 
patients whereas in those more than 40 years of age it was 18.34 (P-value $\leq$ 0.005). Comparing the mean LNR, the younger patients had higher LNR than the older (0.31 vs 0.13 ) and the difference was also statistically significant (Table 2 ). Most of the patients $(42 \%)$ had well differentiated tumors. (Figure 2)

Table 2. Comparison of LNR and stage according to age of patients with colorectal cancer.

\begin{tabular}{lrrr} 
& $\begin{array}{r}\leq 40 \text { years } \\
\text { of age }\end{array}$ & $\begin{array}{r}>40 \text { years } \\
\text { of age }\end{array}$ & $p$-value ${ }^{1}$ \\
\hline Mean LNR & $0.32 \pm 0.3$ & $0.13 \pm 0.26$ & 0.013 \\
\hline Median LNR & 0.2 & 0 & 0.003 \\
\hline Mean Stage & $4.8 \pm 2.3$ & $3.4 \pm 2.3$ & 0.009 \\
\hline${ }^{1} p$-value by & & & \\
\hline
\end{tabular}

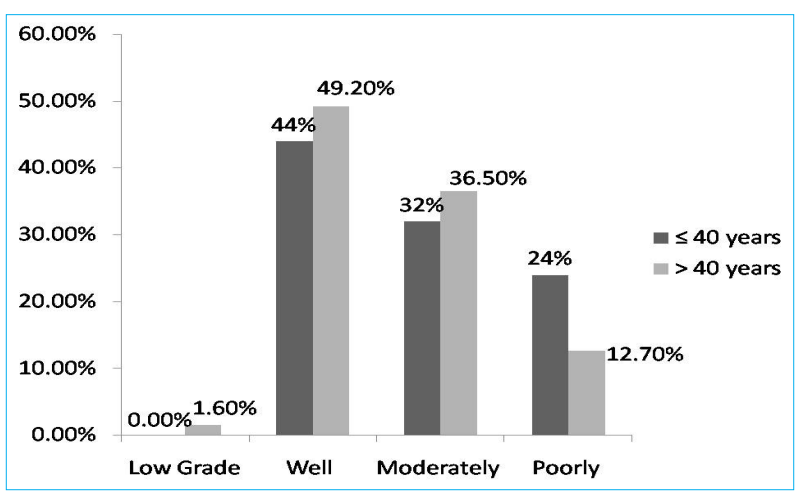

Figure 2. Histopathological grade of tumor.

\section{DISCUSSION}

The overall median age of colorectal cancer presentation was 54 years (males 54, females 52), in the younger age group it was 32 years and in the older it was 56 years.

Colorectal carcinoma (CRC) was found to be twice as common in males compared to females. In our study, colorectal cancer in young adults was observed in $26 \%$ of the patients, which is quite high compared to the rate observed in Europe (3\%) and the United states (20\%). 11,12 However, the proportion of colorectal cancer in young patients observed in our study is comparable to that observed in India and other Asian countries where it ranges from 30 to as high as $43.8 \%{ }^{12,13} \mathrm{~A} 10$ year review from our institute (1999-2008) revealed a total of 234 patients with colorectal cancer. Though there was an increase in the number of young adults with colorectal cancerfrom 28 to 34 over the last 10 years, however, in both groups (recent and early according to the time period), $28 \%$ patients were young. ${ }^{14}$
Young patients have been observed to present colorectal cancer in more advanced stage, with poor morphology and poor prognosis. ${ }^{11}$ In our study, $56 \%$ of patients in the younger age group had stage III disease compared to $34 \%$ in the older age group. Stage II disease, on the other hand, was almost equally common in the two groups, $40 \%$ and $44 \%$, respectively.

Regarding the tumor location, $80 \%$ of the lesions involved the rectum and the left colon and the lesions were more common on the left side in the older than in the young ( $85 \%$ vs $72 \%$ respectively). Though rectal cancer has been reported to be uncommon (3.6\%) in the young patients, in our series, there was not much difference between the two groups ( $44 \%$ in young and $45 \%$ in older).${ }^{15}$ As most of the colon cancers involved left side, in our population, screening sigmoidoscopy could be an effective tool for mass screening in high-risk people.

The current TNM staging system considers the number of lymphnodes positive as a marker of prognosis. ${ }^{16}$ The number of positive nodes is dependent on the number of nodes dissected and the extent of resection of nodes as well as the location of the lesion.Lesions retrieved in the right side of colon are more commonly associated with a high frequency of positive nodes. ${ }^{17,18}$ The dissection of 12 nodes is regarded as adequate for staging colorectal cancer, however, there is a controversy regarding whether this numberis inadequate lead to arisk of understaging. ${ }^{19}$

Increased LNR has been found to be associated with significantly poor overall survival and disease-free survival. ${ }^{20}$ In a meta-analysis of 75,838 node positive patients with colorectal cancer, LNR was observed to have significant weight in the prognosis of patients with colorectal cancer and they recommend LNR to be incorporated in a future staging system for colorectal cancer. ${ }^{10}$

The median number of retrieved nodes and metastatic nodes were 17.5 and 0 (range 1 to 113 and 0 to 112), respectively. It was similar to other studies where the retrieved nodes ranges from 10 to 26.8 nodes, which signifies the adequacy of nodal dissection in our study. ${ }^{10,18}$ The cut off LNR has been reported to be 0.12 to $0.35 .{ }^{10}$ In our series, the mean LNR was 0.31 in the younger patients where as in those above 40 years, it was 0.13 and the difference was statistically significant. Hence, the young patients with colorectal cancer appear to have poorer prognosis than older patients in Nepal. 


\section{CONCLUSIONS}

In our study of colorectal cancer at Tribhuvan University Teaching Hospital, the proportion of young patients was higher than equivalent European studies. Lymph node metastasis seems to be more common in young patients, which is, reflected in a higher LNR and thus a more advanced disease. Therefore, adjuvant chemotherapy should be strongly adviced in this age group. There is also a need for improved awareness of colorectal cancer among the public as well as in caregivers.

\section{REFERENCES}

1. Bailey CE, Hu C, You YN, Bednarski BK, Rodriguez-Bigas MA, Skibber JM, et al. Increasing disparities in the agerelated incidences of colon and rectal cancers in the United States, 1975-2010. JAMA Surg. 2015; 150(1): 17-22.[Full Text]

2. Merrill RM, Anderson AE. Risk-adjusted colon and rectal cancer incidence rates in the United States. Dis Colon Rectum. 2011; 54(10): 1301-6.[Google Scholar]

3. Onerup A, Angenete E, Bock D, et al. The effect of preand post-operative physical activity on recovery after colorectal cancer surgery (PHYSSURG-C): study protocol for a randomised controlled trial. Trials. 2017; 18(1): 212 . [BioMed]

4. Meyer JE, Narang T, Schnoll-Sussman FH, Pochapin MB, Christos PJ, Sherr DL. Increasing incidence of rectal cancer in patients aged younger than 40 years: an analysis of the surveillance, epidemiology, and end results database. Cancer. 2010; 116(18): 4354-9. [Full Text]

5. Sung JJ, Lau JY, Goh KL, Leung WK, Asia Pacific Working Group on Colorectal C. Increasing incidence of colorectal cancer in Asia: implications for screening. Lancet Oncol. 2005; 6(11): 871-6.[Science Direct]

6. Dozois EJ, Boardman LA, Suwanthanma W, et al. Youngonset colorectal cancer in patients with no known genetic predisposition: can we increase early recognition and improve outcome? Medicine (Baltimore). 2008; 87(5): 259-63.[Full Text]

7. Surendra Shah SS, Jay Narayan Shah, Sanjaya Paudyal. Clinico-pathological characteristics of colorectalcarcinoma at university teaching hospital, Nepal. Journal of Patan Academy of Health Sciences. 2014;(2)(2): 4.[Full Text]

8. O'Connell JB, Maggard MA, Livingston EH, Yo CK. Colorectal cancer in the young. Am J Surg. 2004; 187(3): 343-8.[Full Text]

9. Pathy S, Lambert R, Sauvaget C, Sankaranarayanan R. The incidence and survival rates of colorectal cancer in India remain low compared with rising rates in East Asia. Dis Colon Rectum. 2012; 55(8): 900-6.[Full Text]

10. Zhang MR, Xie TH, Chi JL, et al. Prognostic role of the lymph node ratio in node positive colorectal cancer: a meta-analysis. Oncotarget. 2016; 7(45): 72898-907.[Full Text]

11. Orsini RG, Verhoeven RHA, Lemmens VEPP, et al. Comparable survival for young rectal cancer patients, despite unfavourable morphology and more advancedstage disease. European Journal of Cancer. 2015; 51(13): 1675-82. [Google Scholar]

12. You YN, Dozois EJ, Boardman LA, Aakre J, Huebner M, Larson DW. Young-onset rectal cancer: presentation, pattern of care and long-term oncologic outcomes compared to a matched older-onset cohort. Ann Surg Oncol. 2011; 18(9): 2469-76. [Google Scholar]

13. Nath J, Wigley C, Keighley MR, Perakath B. Rectal cancer in young adults: a series of 102 patients at a tertiary care centre in India. Colorectal Dis. 2009; 11(5): 475-9. [Google Scholar]

14. Kansakar P, Singh Y. Changing trends of colorectal carcinoma in Nepalese young adults. Asian Pac J Cancer Prev. 2012; 13(7): 3209-12.

15. O’Connell JB, Maggard MA, Liu JH, Etzioni DA, Ko CY. Are survival rates different for young and older patients with rectal cancer? Dis Colon Rectum. 2004; 47(12): 2064-9.[Google Scholar]

16. Jessup JM GR, Aware EA,, editor. Colon and Rectum.: AJCC Cancer Staging Manual. 8th ed. Chicago: AJCC. 2017[Google Scholar]

17. Gelos M, Gelhaus J, Mehnert P, et al. Factors influencing lymph node harvest in colorectal surgery. Int J Colorectal Dis. 2008; 23(1): 53-9. Google Scholar]

18. Li Destri G, Di Carlo I, Scilletta R, Scilletta B, Puleo S. Colorectal cancer and lymph nodes: the obsession with the number 12. World J Gastroenterol. 2014; 20(8): 1951-60. [Full Text]

19. McDonald JR, Renehan AG, O’Dwyer ST, Haboubi NY. Lymph node harvest in colon and rectal cancer: Current considerations. World J Gastrointest Surg. 2012; 4(1): 9-19.[Full Text]

20. Zeng WG, Zhou ZX, Wang Z, et al. Lymph node ratio is an independent prognostic factor in node positive rectal cancer patients treated with preoperative chemoradiotherapy followed by curative resection. Asian Pac J Cancer Prev. 2014; 15(13): 5365-9.[Full Text] 